\title{
No Metathesis in Harmonic Serialism
}

\author{
Chikako Takahashi \\ Stony Brook University
}

\section{Introduction}

Metathesis usually refers to the transposition of two segments, although the term has also been used more generally to refer to any reordering of linear segments (Hume 2001, Blevins and Garrett 2004, Chandlee 2014, Canfield 2015). Unlike other phonological processes such as epenthesis or deletion, metathesis has often been described as a 'sporadic' and 'non-regular' pattern because of its rarity (Montreuil 1981 cited in Hume 2001, Powell 1985). However, recent work has claimed that metathesis does not differ much from other more commonly-discussed phonological processes and can be readily analyzed within the Optimality Theory (OT) framework (Buckley 2011, Chandlee 2014, Canfield 2016; see Chandlee 2014 for a computational analysis of metathesis).

Examples of synchronic metathesis come from languages such as Rotuman, Leti, Palestinian Arabic, Fur, and Hebrew, among others (Canfield 2016). Almost all of the attested synchronic metathesis cases involve adjacent segments. Synchronic long-distance metathesis, involving non-adjacent segments, is rare at best and limited to a few cases involving affixation. Both $\mathrm{CC}$ and $\mathrm{CV}(\mathrm{VC})$ metathesis involving various segments are attested, while VV metathesis has been claimed not to exist (McCarthy 2000, Mielke \& Hume 2001, Canfield 2015). In some languages such as Rotuman or Kwara'ae, the segments involved in CV reordering encompass the entire inventory of consonants and vowels. However, in most observed synchronic cases of $\mathrm{CC}$ reordering, the segments involved in each language are restricted to specific consonants.

Previous Parallel OT (P-OT) analyses of metathesis treat the relevant phonological operation as a reordering of segments with a violation of the faithfulness constraint LINEARITY which requires the output segments to keep the precedence relations of the input. However, the constraint LINEARITY has been argued to pose both conceptual and empirical problems (Carpenter 2002, Heinz 2005, Canfield 2015), most notably that analysis of metathesis in P-OT which relies on the constraint LINEARITY overgenerates, allowing unattested patterns to surface. In contrast, a derivational version of Optimality Theory, Harmonic Serialism (HS), has been argued to correctly fail to generate unattested metathesis patterns such as long-distance metathesis (McCarthy 2007a).

Harmonic Serialism, a serial version of OT (McCarthy and Pater 2016), assumes a series of intermediate stages in the process of deriving the surface form, unlike P-OT, which assumes direct mapping from the input to the output. One of the major differences between P-OT and HS lies in its GEN. Candidates generated by GEN in HS can only be minimally different from the input at each stage. In other words, only one operation can be applied to the input to generate each candidate. At each intermediate stage, the harmony is set to 'gradually' improve (McCarthy 2010). This gradualness is believed to block unattested metathesis such as long-distance metathesis, solving the empirical problems with LINEARITY found in P-OT (McCarthy 2007a).

However, whether or not reordering of segments is a primitive operation in GEN remains an open question. Compared to operations such as deletion and epenthesis, which have ample support crosslinguistically, metathesis is observed less frequently (Mielke \& Hume 2001). In addition, there is an asymmetry between the segments involved in $\mathrm{CV}$ and $\mathrm{CC}$ metathesis. While many $\mathrm{CV}$ metathesis operations involve a language's entire segment inventory, $\mathrm{CC}$ metathesis is typically limited to specific consonants. This asymmetry is not explained by the LINEARITY constraint, which does not impose restrictions on segments that can be reordered.

In this paper, I will propose that metathesis need not be an operation in GEN, since most of the attested

\footnotetext{
* I would like to thank Michael Becker for his great advising and support. I would also like to thank Ellen Broselow, Christina Bethin, Jeff Heinz, Andrew Lamont, Peter Cuce, colleagues at Stony Brook, audience at PhoNE 2017, and anonymous reviewers of this abstract for their helpful comments and questions. All the errors in this paper are mine.
} 
synchronic metathesis cases can be analyzed in HS as a combination of more common operations such as copying + deletion or fusion + fission rather than a single operation of reordering

First I present a serial OT analysis of Rotuman metathesis as copy + deletion and compare it to an existing parallel OT analysis. In Section 3, I provide an analysis of the same Rotuman pattern with transposition as an atomic operation in Harmonic Serialism, and illustrate a potential problem it poses. Section 4 explains why the copy + deletion analysis is preferred. A non-transposition analysis of apparent CC metathesis is presented in Section 5. The discussion and conclusion follow.

\section{Rotuman metathesis as copy + deletion}

In this section I provide an analysis of three types of alternations in Rotuman, an Austronesian language which shows apparent metathesis, deletion and umlaut. I demonstrate how copy + deletion with a subsequent fusion, can be carried out in Harmonic Serialism to account for all of the observed patterns.

2.1 Rotuman metathesis The alternation between 'complete' and 'incomplete' phases (Churchward 1940, Besnier 1987, Blevins 1994, Hale \& Kissock 1998, McCarthy 2000) involves apparent metathesis (1a), as well as apparent deletion (1b) and umlaut (1c). I will analyze all three patterns as copying followed by deletion, which in the cases of (1b) and (1c) is then followed by fusion when the sonority of the final vowel is not greater than the sonority of the penultimate vowel.

(1) Rotuman Phase Differences

(a) Metathesis

(b) Apparent Deletion

(c) Umlaut

\begin{tabular}{|c|c|c|}
\hline Complete & Incomplete & \\
\hline i?a & ia? & 'fish' \\
\hline seseva & seseav & 'erroneous' \\
\hline pure & puer & 'to rule' \\
\hline tokiri & tokir & 'to roll' \\
\hline ti?u & ti? & 'big' \\
\hline rako & rak & 'to imitate' \\
\hline hoti & høt & 'to embark' \\
\hline mose & møs & 'to sleep' \\
\hline futi & fyt & 'to pull' \\
\hline
\end{tabular}

While differences between the two phases were considered to be morphological or syntactic by Churchward (1940) and McCarthy (1995), among others, McCarthy's (2000) analysis of the phase alternation in Rotuman assumes that the alternations are phonological phenomena (also see Hale and Kissock 1998). Complete Phase forms are generally used when they precede monosyllabic suffixes (or clitics), while Incomplete Phase forms are used before polysyllabic suffixes/clitics. Although it is intriguing to consider incorporation of differences in suffix length in the two phases into the analysis, for the sake of simplicity and to focus on the observed alternations, I analyze the words in two phases as isolated words. I will also follow McCarthy (2000) and Hale and Kissock (1998) in assuming that both phases are derived from a UR that is similar to the surface form in the Complete Phase.

Since Rotuman stress is trochaic, and the Incomplete Phase always ends in a stressed syllable, stressed syllables in Incomplete Phase words are always heavy (to satisfy SWP). Following McCarthy (2000), I assume that coda consonants are moraic (see McCarthy 2000 for the argument for assigning a mora to a coda), making CVC syllables heavy.

When the last two vowels in each word are rising in sonority, the last CV in the word undergoes metathesis. When the two vowels do not rise in sonority, the last vowel does not surface in the output (apparent deletion) or the two vowels coalesce (Umlaut) depending on the combination of the vowels. The umlaut cases are observed only when the vowel sequence consists of back + front vowels.

2.2 Proposal I propose that all of the alternation patterns result from copy + deletion operations driven by the STRESS-To-Weight Principle (SWP; Prince 1990), FinAL STRESS (Inkelas 1994) and subsequent vowel fusion to satisfy sonority requirements on light diphthongs (VV sequence in closed syllables). 
(2) SWP: Assign a violation mark to every stressed syllable that is not heavy.

(3) FINALSTRESS: Assign a violation mark to a word final syllable that does not bear a stress.

(4) INTEGRITY: No element of $\mathrm{S}_{1}$ has multiple correspondents in $\mathrm{S}_{2}$.

With the constraint SWP highly ranked, the first step of the derivation (after stress assignment) outputs the intermediate winner /púr $\mathrm{e}_{2} / \rightarrow /$ púe $_{2} \mathrm{r}_{1} \mathrm{e}_{2}$ / through copying of a vowel, as shown in (5) I assume MAX is undominated in this language, prohibiting deletion of a segment (apparent 'deletion' cases in the Incomplete Phase will be discussed below). Copying of a vowel incurs a violation mark under INTEGRITY (McCarthy and Prince 1995), which prohibits an input segment from having multiple corresponding segments in the output. I assume that INTEGRITY bans co-indexed output segments that have one corresponding segment in the input, but that insertion of the copied segment does not violate general DEP since the segment does have a correspondent in the input. Although (5b) violates FINALSTRESS, because the stressed syllable 'púe' is not the final syllable of the word, it still comes out as the winner at this stage since the stressed syllable is heavy, and the SWP requirement is met without deleting the final $\mathrm{V}$.

(5) Step 1: /púr $\mathrm{e}_{2} / \rightarrow /$ púe $_{2} \mathrm{r}_{1} \mathrm{e}_{2} /$

\begin{tabular}{|c|c|c|c|c|c|}
\hline$/ \mathrm{pú}_{1} \mathrm{re}_{2} /$ & MAX & DEP & SWP & FINALSTRESS & INTEGRITY \\
\hline a. $\mathrm{pú}_{1} \mathrm{re}_{2}$ & & & $* !$ & $*$ & \\
\hline b. pú $\mathrm{u}_{1} \mathrm{e}_{2} \mathrm{re}_{2}$ & & & & $*$ & $*$ \\
\hline c. $\mathrm{pú}_{1} \mathrm{r}$ & $* !$ & & & & \\
\hline
\end{tabular}

In the next step, /pú $\mathrm{e}_{2} \mathrm{re}_{2} / \rightarrow / \mathrm{pú}_{1} \mathrm{e}_{2} \mathrm{r} /$, the faithful candidate púe ${ }_{2} r_{1} e_{2}$ loses, due to its violation of FINALSTRESS. The deletion of the co-indexed vowel does not violate MAX since each input segment coindexed with ' 2 ' does have a corresponding segment in the output (for correspondence involving a copied segment, see Stanton and Zukoff 2015). McCarthy (2016: 12-13) questions the need for indexation in Harmonic Serialism; if so, the operation in (6) would have to be construed as reabsorption of the copied vowel rather than deletion proper. However, I postulate that the copied vowels gain special status and are marked as copies of each other, an assumption that is crucial to this analysis.

(6) Step 2: /púe ${ }_{2} \mathrm{r}_{1} \mathrm{e}_{2} / \rightarrow /$ púe $_{2} \mathrm{r}_{1} /$

\begin{tabular}{|c|c|c|c|c|c|}
\hline$/$ púe $_{2} \mathrm{r}_{1} \mathrm{e}_{2} /$ & MAX & DEP & SWP & FINALSTRESS & INTEGRITY \\
\hline a. púe ${ }_{2} \mathrm{r}_{1} \mathrm{e}_{2}$ & & & & $* !$ & $(*)$ \\
\hline b. púe ${ }_{2} \mathrm{r}_{1}$ & & & & & \\
\hline
\end{tabular}

Apparent deletion cases such as $/ \mathrm{ra}_{1} \mathrm{ko}_{2} /$ to [rá ${ }_{12} \mathrm{k}$ ] can also be analyzed as copy + deletion followed by vowel fusion. The proposed derivational path is shown in (7) adapting a version of HS tableaux presented in Pruitt (2012). This derivation assumes that the stress is assigned first by highly ranked prosodic constraints not shown here. The constraint LIGHT-DIPH bans the VV sequence of non-rising sonority in a closed syllable (McCarthy 2000). Although fusing two vowels together violates UNIFORMITY (McCarthy \& Prince 1995), which militates against an output segment that corresponds to two segments in the input, the given constraint ranking derives $\left[\mathrm{rá}_{1,2} \mathrm{k}\right]$ with a fused vowel as the most harmonic output.

(7) Derivational path from $/ \mathrm{rá}_{1} \mathrm{ko}_{2} /$ to [rá $\left.{ }_{12} \mathrm{k}\right]$

\begin{tabular}{|c|c|c|c|c|c|c|}
\hline$/$ rá $_{1} \mathrm{ko}_{2} /$ & & SWP & $\begin{array}{c}\text { FINAL } \\
\text { STRESS }\end{array}$ & LIGHT-DIPH & UNIFORMITY & INTEGRITY \\
\hline UR & rá $_{1} \mathrm{ko}_{2}$ & $*$ & $*$ & & & \\
\hline $\begin{array}{l}\text { Add weight to the } \\
\text { stressed } \sigma\end{array}$ & $\hookrightarrow \mathrm{rá}_{1} \mathrm{O}_{2} \mathrm{kO}_{2}$ & & $*$ & $*$ & & $*$ \\
\hline Align $\sigma$ & $\rightarrow \mathrm{rá}_{1} \mathrm{O}_{2} \mathrm{k}$ & & & $*$ & & \\
\hline $\begin{array}{l}\text { Resolve *VV with } \\
\text { non-rising sonority }\end{array}$ & $\hookrightarrow$ rá $_{1,2} \mathrm{k}$ & & & & * & \\
\hline
\end{tabular}


Support for the fusion analysis comes from Umlaut cases such as /hoti/ $\rightarrow$ høt ('to embark'). Steps shown in (8) (9) exhibit the same stages as the derivation of $/ \mathrm{rá}_{1} \mathrm{ko}_{2} /$ to $\left[\mathrm{rá}_{12} \mathrm{k}\right]$ in (7) The only difference is the change in vowel quality observed in the final output. ${ }^{1}$

(8) Step 1: /hó $\mathrm{ti}_{2} / \rightarrow /$ hó $_{1} \mathrm{i}_{2} \mathrm{ti}_{2} / \quad \rightarrow \quad$ Step 2: $/$ hó $_{1} \mathrm{i}_{2} \mathrm{ti}_{2} / \rightarrow /$ hó $_{1} \mathrm{i}_{2} \mathrm{t} /$

(9) Step 3: /hó ${ }_{1} \mathrm{i}_{2} \mathrm{t} / \rightarrow / \mathrm{h}_{12} \mathrm{t} /$

\begin{tabular}{|c|c|c|c|c|c:c|}
\hline$/$ hó $_{1} \mathrm{i}_{2} \mathrm{t} /$ & MAX & SWP & FINAL STRESS & LIGHT-DIPH & UNIFORMITY & INTEGRITY \\
\hline a. hó ${ }_{1} \mathrm{i}_{2} \mathrm{t}$ & & & & $* !$ & & \\
\hline b. hó ${ }_{12} \mathrm{t}$ & & & & & $*$ & $\vdots$ \\
\hline
\end{tabular}

2.3 Parallel-OT analyses In contrast to the analysis outlined above, McCarthy's (2000) Parallel-OT analysis of Rotuman phase alternation depends on the ranking of LIGHT-DIPH, FINAL STRESS (ALIGN-HEAD$\sigma$ in his analysis) $>>$ MAX $>$ LINEARITY to account for both metathesis and deletion cases. The summary tableau adapted from McCarthy (2000) is shown in (10)

(10) A summary tableau adapted from (McCarthy 2000: 21).

a. Metathesis case

\begin{tabular}{|c|c|c|c|c|}
\hline$/ \mathrm{pu}_{1} \mathrm{re}_{2} /$ & LIGHT-DIPH & FINAL STRESS & MAX & LINEARITY \\
\hline a. $\left(\mathrm{pu}_{1} \mathrm{e}_{2} \mathrm{r}\right)$ & & & & $* !$ \\
\hline b. $\quad\left(\mathrm{pu}_{1} \mathrm{r}\right)$ & & & $* !$ & \\
\hline c. $\quad\left(\mathrm{pú}_{1} \cdot \mathrm{re}_{2}\right)$ & & $* !$ & & \\
\hline
\end{tabular}

b. Deletion case

\begin{tabular}{|c|c|c|c|c|}
\hline$/ \mathrm{ra}_{1} \mathrm{ko}_{2} /$ & LIGHT-DIPH & FINAL STRESS & MAX & LINEARITY \\
\hline a. $\left(\mathrm{ra}_{1} \mathrm{k}\right)$ & & & $*$ & \\
\hline b. $\quad\left(\mathrm{ra}_{1} \mathrm{O}_{2} \mathrm{k}\right)$ & $* !$ & & & * \\
\hline c. $\quad\left(\mathrm{rá}_{1} \cdot \mathrm{ko}_{2}\right)$ & & $* !$ & & \\
\hline d. $\quad\left(\mathrm{rO}_{2} \mathrm{k}\right)$ & & & * & $* !$ \\
\hline
\end{tabular}

However, as pointed out in Carpenter (2002), this constraint ranking does not rule out a problematic candidate such as ' $\mathrm{ro}_{2} \mathrm{ak}_{1}$ ' with long-distance metathesis as shown in (11) The intended winner rak loses against the added candidate $\mathrm{ro}_{2} a k_{1}$, since even with the two violation marks on LINEARITY, $\mathrm{ro}_{2} a k_{1}$ does not violate any of the markedness constraints or MAX. A problematic candidate is added to the summary tableau above.

McCarthy's (2000) Parallel OT analysis of $/ \mathrm{rak}_{1} \mathrm{O}_{2} / \rightarrow\left[\mathrm{rak}_{1}\right]$

\begin{tabular}{|c|c|c|c|c|}
\hline$/ \mathrm{ra}_{1} \mathrm{ko}_{2} /$ & LIGHT-DIPH & FINAL STRESS & MAX & LINEARITY \\
\hline (2) a. $\mathrm{ra}_{1} \mathrm{k}$ & & & $* !$ & \\
\hline b. $\quad \mathrm{ra}_{1} \mathrm{O}_{2} \mathrm{k}$ & $* !$ & & & * \\
\hline c. rá $\mathrm{k}_{1} \cdot \mathrm{ko}_{2}$ & & $* !$ & & \\
\hline d. $\mathrm{ro}_{2} \mathrm{k}$ & & & $* !$ & $*$ \\
\hline e. $\quad \mathrm{ro}_{2} \mathrm{a}_{1} \mathrm{k}$ & & & & $* *$ \\
\hline
\end{tabular}

1 Treatment of vowel fusion requires further investigation. While some have proposed that fusion is a primitive operation (Fallon 1998), others consider it to be the result of assimilation + deletion. As we have seen above, highly ranked MAX eliminates the possibility of analyzing fusion as assimilation + deletion. However, analyzing fusion as an operation is problematic in HS since fusing two segments into one violates more than one IDENT constraint. As McCarthy (2007) notes, if we assume that GEN can only do one unfaithful mapping, a fused vowel cannot appear as a candidate in HS derivation when it involves the change of multiple features. Although detailed analysis of vowel fusion in HS requires further investigation, it is possible to view the vowel fusion in Rotuman 'oi' $\rightarrow$ ' $\varnothing$ ' as a gradual series of assimilation operations followed by a fusion of identical vowels. This way, only one faithfulness violation is introduced at each step. HS analysis of fusion has not yet been proposed (McCarthy 2016, footnote 8), but this is one possible way to incorporate it. 
Consideration of candidates such as (11e) $\mathrm{ro}_{2} a k_{1}$ leads Carpenter (2002) to conclude that the constraint LINEARITY alone cannot block reordering of the segments that span a certain distance, and to propose a family of ADJACENCY(domain) constraints, faithfulness constraints that require "segments or features to maintain, in the output, the immediate proximity found in the input." (p. 5). This specified domain helps treat various types of metathesis differently. For instance, Carpenter utilizes I-ADJACENCY $(\boldsymbol{\sigma})$ to account for Rotuman metathesis patterns. I-ADJACENCY $(\boldsymbol{\sigma})$, which requires that segments within a syllable in the input stay adjacent to each other in the output, successfully eliminates any non-adjacent metathesis candidate that does not surface in this language. The non-adjacent metathesis form (12e) roak thus incurs two violation marks, since the adjacency between the two segments ' $\mathrm{r}-\mathrm{a}$ ' and ' $\mathrm{k}-\mathrm{o}$ ' in two syllables in the input is not maintained in the output (Carpenter assumes that the alternate form [rak] in the Incomplete phase is derived from complete form [ra.ko]). ${ }^{2}$

Rotuman non-adjacent metathesis blocked with I-ADJACENCY $(\boldsymbol{\sigma})$ (Carpenter 2002: 8)

\begin{tabular}{|c|c|c|c|c|c|}
\hline [ra.ko] & LIGHT-DIPH & ALIGN-HEAD- $\boldsymbol{\sigma}$ & ADJACENCY $(\boldsymbol{\sigma})$ & MAX & LINEARITY \\
\hline a. rak & & & & $*$ & \\
\hline b. raok & $* !$ & & * & & $*$ \\
\hline c. rá.ko & & $* !$ & & & \\
\hline d. rok & & & $* !$ & $*$ & $*$ \\
\hline e. roak & & & $* ! *$ & & \\
\hline
\end{tabular}

The P-OT analysis works by proliferating a family of faithfulness constraints without which it would be difficult to block unattested patterns.

The analysis of the Rotuman phase alternations provided in this section showed that metathesis is not needed as an operation in HS, and seemingly different alternation patterns all result from sequential operations of copy + deletion and subsequent vowel fusion. What is crucial for the proposed HS analysis of Rotuman is to rank MAX high, as opposed to McCarthy's (2000) P-OT analysis in which MAX had to be dominated by LighT-DiPH. Furthermore, a long-distance metathesis candidate such as roak, which was problematic in P-OT, did not surface in the copy + deletion HS analysis because of the gradualness of GEN.

If gradualness of GEN is responsible for blocking long-distance patterns, are there any advantages to analyzing metathesis as copy + deletion instead of transposition? Or is a transposition analysis in HS equally capable of deriving the correct patterns? The next section shows how LINEARITY could be problematic even in a Harmonic Serialism framework.

\section{LINEARITY in Harmonic Serialism}

In this section I show that Rotuman metathesis patterns pose a potential problem when analyzed as transposition even in Harmonic Serialism, and that the copy + deletion (and subsequent fusion) analysis does not.

Metathesis in HS has always been analyzed as a transposition violating the LINEARITY (e.g., McCarthy 2007, Torres-Tamarit et al. 2012, Elfner 2016). McCarthy (2007) demonstrates, using a toy language, that the gradualness of GEN blocks unattested long-distance metathesis that would otherwise be a problem in POT analysis (as pointed out by Carpenter 2002).

First, let us derive the apparent metathesis pattern ( $\mathrm{pú}_{1} \mathrm{re}_{2} \rightarrow$ pú $_{1} \mathrm{e}_{2} \mathrm{r}$ ) with transposition as an atomic operation in HS. After stress assignment, the first step derives the optimal output (pú $\mathrm{e}_{2} \mathrm{r}$ ). The next step converges on the same winner since the pú $_{1} \mathrm{e}_{2} \mathrm{r} \rightarrow$ pú $_{1} \mathrm{e}_{2} \mathrm{r}$ mapping does not violate any of the constraints discussed.

\footnotetext{
2 McCarthy (2000) claims that a candidate such as $\mathrm{ro}_{2} a k_{l}$ will not surface because it involves VV and/or long-distance metathesis, both of which are not attested synchronic patterns. He indicates that a specific LINEARITY constraint banning VV transposition or non-adjacent transposition will dominate the general LINEARITY constraint, a solution similar to that of Carpenter (2002).
} 
First step after stress assignment: pú $_{1} \mathrm{re}_{2} \rightarrow$ pú $_{1} \mathrm{e}_{2} \mathrm{r}$

\begin{tabular}{|c|c|c|c|c|c|}
\hline$/ \mathrm{pú}_{1} \mathrm{re}_{2} /$ & MAX & SWP & FINAL STRESS & LIGHT-DIPH & LINEARITY \\
\hline a. $\quad\left(\mathrm{pú}_{1} \mathrm{re}_{2}\right)$ & & $* !$ & * & & \\
\hline b. $\left(\mathrm{pú}_{1} \mathrm{e}_{2} \mathrm{r}\right)$ & & & & & $*$ \\
\hline c. $\quad\left(p u_{1} r\right)$ & $* !$ & & & & \\
\hline d. $\quad\left(p^{\prime} u_{1} \mathrm{e}_{2}\right)$ & *! & & & & \\
\hline
\end{tabular}

The undominated MAX is crucial in this analysis in order to derive both apparent deletion and umlaut patterns. In the umlaut case shown below, since we can only make one change at a time, [hó ${ }_{1} \mathrm{i}_{2} \mathrm{t}$ ] is the necessary intermediate winner in deriving the surface form [hǿ $\left.{ }_{12} \mathrm{t}\right]$. Without the higher ranked MAX, an undesired winner such as [hó $1 \mathrm{t}$ ] could surface, satisfying all of the crucial markedness constraints.

At the first step (assuming the stress is already assigned previously) $/ \mathrm{hó}_{1} \mathrm{ti}_{2} / \rightarrow\left[\mathrm{ho}_{1} \mathrm{i}_{2} \mathrm{t}\right]$

\begin{tabular}{|c|c|c|c|c|c|c|}
\hline$/$ hó $_{1} \mathrm{ti}_{2} /$ & MAX & SWP & FINAL STRESS & LIGHT-DIPH & LINEARITY & UNIFORMITY \\
\hline a. $\quad\left(\right.$ hó $\left._{1} \mathrm{ti}_{2}\right)$ & & *! & $*$ & & & \\
\hline b. $\left(h_{1} \mathrm{i}_{2} \mathrm{t}\right)$ & & & & $*$ & $*$ & \\
\hline c. $\quad\left(h^{\prime} o_{1} t\right)$ & $* !$ & & & & & \\
\hline
\end{tabular}

Second step: /hó ${ }_{1} \mathrm{i}_{2} \mathrm{t} / \rightarrow\left[\mathrm{h}_{12} \mathrm{t}\right]$

\begin{tabular}{|c|c|c|c|c|c|c|}
\hline /hó ${ }_{1} \mathrm{i}_{2} \mathrm{t} /$ & MAX & SWP & FINAL STRESS & LIGHT-DIPH & LINEARITY & UNIFORMITY \\
\hline a. $\quad\left(\right.$ hó $\left._{1} \mathrm{i}_{2} \mathrm{t}\right)$ & & & & $* !$ & & \\
\hline b. $\left(\mathrm{h}_{12} \mathrm{t}\right)$ & & & & & & $*$ \\
\hline c. $\quad\left(\mathrm{hi}_{2} \mathrm{o}_{1} \mathrm{t}\right)$ & & & & & $* !$ & \\
\hline
\end{tabular}

At the second step, the candidate $\left(h_{12} \mathrm{t}\right.$ ), which satisfies LIGHT-DIPH, surfaces as the winner. The other LIGHT-DIPH satisfying candidate ( $\mathrm{hi}_{2} \mathrm{o}_{1} \mathrm{t}$ ) does not surface because the violation of LINEARITY is more costly than the violation of UNIFORMITY given the ranking LINEARITY $>$ UNIFORMITY.

It appears that highly ranked MAX is necessary to provide a unified account for Rotuman alternation patterns whether we consider metathesis as one operation violating LINEARITY or as a sequence of copy + deletion operations. However, this ranking commits us to a non-deletion analysis, contra McCarthy's Parallel OT analysis (2000), demonstrating that apparent deletion (rako $\rightarrow$ rak) indeed involves vowel coalescence.

Gradualness of GEN in Harmonic Serialism appears to block unattested long-distance metathesis patterns in Rotuman with help from other faithfulness constraints (Undominated MAX and lower ranking of UNIFORMITY). However, when we turn to onsetless /VCV/ $\rightarrow$ [VVC] alternations, shown in (16) a problem arises.

Problematic cases for the transposition analysis (Churchward 1940)

$\begin{array}{lll}\text { Complete } & \text { Incomplete } & \\ \text { i?a } & \text { ia? } & \text { 'fish' } \\ \text { esu } & \text { es } & \text { 'papaya' } \\ \text { o?i } & \varnothing ? & \text { 'parent' }\end{array}$

Allowing transposition as an operation in Harmonic Serialism permits only one transposition of adjacent segments at a time, so there is no difference between $/ i_{1} ?_{2} a_{3} / \rightarrow\left(i_{1} a_{3} P_{2}\right)$ and $/ i_{1}{ }_{2} a_{3} / \rightarrow\left(2_{2} i_{1} a_{3}\right)$. Onsetlessness of the first syllable creates the possibility of transposing the $\mathrm{VC}$ to create an onset. Thus, the unintended winner $\left(?_{2} i_{1} a_{3}\right)$ in $(17 d)$ could surface, satisfying all of the relevant markedness constraints.

\begin{tabular}{|c|c|c|c|c|c|c|}
\hline$/ i_{1}{ }_{2} a_{3} / \rightarrow\left[i_{1} a_{3} ?\right.$ & & & & & & \\
\hline $\mid i_{1} \mathrm{P}_{2} \mathrm{a}_{3} /$ & MAX & SWP & FINAL STRESS & LIGHT-DIPH & LINEARITY & UNIFORMITY \\
\hline a. $\quad\left(i_{1} ?_{2} a_{3}\right)$ & & $* !$ & & & & \\
\hline b. $\left(i_{1} a_{3} P_{2}\right)$ & & & & & $*$ & \\
\hline c. $\quad\left(i_{1} ?_{2}\right)$ & $* !$ & & & & & \\
\hline d. $\left(P_{2} i_{1} a_{3}\right)$ & & & & & $*$ & \\
\hline
\end{tabular}


On the other hand, if we do not assume transposition as an atomic operation, the pattern has to be derived through sequential operations of copy + deletion via the derivational path $/ i_{1} \mathrm{~Pa}_{2} / \rightarrow i_{1} \mathrm{a}_{2} \mathrm{~Pa}_{2} \rightarrow\left[i_{1} \mathrm{a}_{2}\right.$ ?]. An undesirable intermediate output such as (19d) $\left(?_{2} i_{1} a_{3}\right)$ will not surface since this would involve consonant copying ( $/ \hat{1}_{1}{ }_{2} \mathrm{a}_{3} / \rightarrow \mathrm{P}_{2} \hat{1}_{1} \mathrm{P}_{2} \mathrm{a}_{3} \rightarrow \mathrm{P}_{2} \mathbf{1}_{1} \mathrm{a}_{3}$ ), which does not improve harmony. In the transposition analysis, the undesirable (17d) could be blocked with a constraint Anchor-Left (McCarthy \& Prince 1995), requiring the leftmost segment to have a correspondent at the left edge of the input. However, this constraint would not even be needed in the copy + deletion analysis.

\section{Why copy + deletion?}

The previous section demonstrated that analyzing alternation patterns in Rotuman as transposition with subsequent fusion is possible in $\mathrm{HS}$ but this poses a problem for $/ \mathrm{V}_{1} \mathrm{CV}_{2} / \rightarrow\left[\mathrm{V}_{1} \mathrm{~V}_{2} \mathrm{C}\right]$ cases, allowing undesirable output forms to surface. There are also other reasons to prefer non-transposition analysis of apparent metathesis in HS. I summarize several additional motivations to prefer the copy + deletion analysis.

Blevins and Garrett (1998) describe Rotuman metathesis as "the result of foot-internal compensatory coarticulation coupled with weak vowel loss" (p. 534). Their view can be interpreted as a vowel copying leftward $\left(/ \mathrm{CV}_{1} \mathrm{CV}_{2} / \rightarrow\left[\mathrm{CV}_{1} \mathrm{~V}_{2} \mathrm{CV}_{2}\right]\right)$ followed by deletion of the final vowel $/ \mathrm{CV}_{1} \mathrm{~V}_{2} \mathrm{CV}_{2} / \rightarrow\left[\mathrm{CV}_{1} \mathrm{~V}_{2} \mathrm{C}\right]$.

Stronger support comes from another Austronesian language, Kwara'ae, which exhibits intermediate stage forms with a copied vowel but without complete deletion. For instance, while /salo/generally becomes [saol] in the speech register called Normal form, [saolo] with a devoiced vowel is optionally observed (Heinz 2005a). Furthermore, the full final vowel will remain, as in /salo/ $\rightarrow$ [saoló], when the word is placed at a syntactically focused position with the final syllable stressed. These patterns would call for a complex derivation if we assume that $\mathrm{CV}$ transposition is involved, necessitating an additional copying of the vowel at the final step $/ \mathrm{sa}_{1} \mathrm{lo}_{2} / \rightarrow \mathrm{sa}_{1} \mathrm{O}_{2} \mathrm{l} \rightarrow\left[\mathrm{Sa}_{1} \mathrm{O}_{2} \mathrm{lo}_{2}\right]$ (for a related problem in P-OT analysis, see Heinz 2005b). On the other hand, it can be straightforwardly explained if we assumed that the derivation involves copy + deletion: the derivational steps stop when there is a requirement to stress the final syllable (at the utterance final position), blocking the deletion of the original vowel. Similar cases of intermediate stage forms are also proposed to exist in Mohawk (Michelson 1988).

\section{CC metathesis as fusion + fission}

We have seen that apparent CV metathesis in Rotuman can be readily analyzed as a pattern resulting from copy + deletion. The non-transposition analyses can be extended to other CV metathesis cases found in Leti (van Engelenhoven 1994 cited in Hume 1998), Kwara'ae (Heinz 2004) and Palestinian Arabic (OSU 2017), although these are not recapitulated here due to space limitations. One might ask, then, if this analysis can also be extended to other types of metathesis. This section seeks to answer the question of whether or not attested synchronic CC metathesis also involves copy + deletion operations, and if not, what other operations could potentially replace metathesis.

Balangao, an Austronesian language spoken in the Philippines, exhibits synchronic CC metathesis. In Balangao, onsets are required and a coda consonant is allowed. CC sequence is allowed only when an affix is attached. Upon affixation, the vowel gets deleted when its stress is removed or when it is a part of an open or unstressed syllable, although it is difficult to predict the vowel deletion pattern (Shelter 1976, Canfield 2015). When vowel deletion creates a glottal + plosive sequence, it surfaces as plosive + glottal as shown in (18)

(18) CC metathesis in Balangao (Adapted from Canfield 2015, Hume 2004, and Shelter 1976).
a. $/ \mathrm{i} \dot{\mathrm{i}}+$ higip/ $\rightarrow$ Pighip 'bring in'
b. $/ \mathrm{ma}+\mathrm{hidim} / \rightarrow$ madhim 'night'
c. $/ \mathrm{p} \Lambda$ hid $+\mathrm{in} / \rightarrow$ p $\Lambda$ dhin $\quad$ 'allow, accept'
d. /gihib + in/ $\rightarrow$ gibhin 'burn it'

While we might wonder if it is possible to account for these patterns as copy + deletion, this series of operations does not seem to be helpful for most cases of CC metathesis because the intermediate stage with a copied segment does not usually improve harmony when $C_{1} C_{2}$ becomes $C_{2} C_{1} C_{2}$, or $C_{1} C_{2} C_{1}$. Instead, I propose that Balangao's apparent CC metathesis results from fusion + fission. 
Following Canfield's (2015) analysis, I assume the glottal-plosive sequence is dispreferred by a constraint such as *GLOTTAL-PLOSIVE. In HS, avoidance of such a sequence can be achieved by a series of operations that affect intermediate stages while improving harmony, but the direct effect of these operations is not necessarily obvious in the surface form.

What is crucial in the 'metathesized' surface form is that all of the input segments are present in the output. This can be achieved by fusing two adjacent segments to create a complex segment and then 'unpacking' them at the next step. For instance, take a derivation such as (19) The post-vowel-deletion intermediate input, $/ \mathrm{Pih}_{1} \mathrm{~g}_{2} \mathrm{ip} /$, can surface as [ $\mathrm{Pig}_{1,2}^{\mathrm{h}}{ }_{1, \mathrm{p}}$ ] by docking the $/ \mathrm{h} / \mathrm{on} / \mathrm{g} /$ to create a complex segment $\mathrm{g}_{1,2}^{\mathrm{h}}$. However, because of $*$ COMPSEG (Padgett 2005) ${ }^{3}$, which militates against a complex segment, the candidates will not converge at this stage. At Step 2, an 'unpacked' candidate $/ \mathrm{iqg}_{2} \mathrm{~h}_{1} \mathrm{ip} / \mathrm{wins}$ (and converges at the following step). Such 'unpacking' of the complex segment has been seen in cases of preaspiration in Icelandic (Heimisdóttir 2014).

(19) Balangao derivations without transposition

Step 1: $/ \mathrm{Pih}_{1} \mathrm{~g}_{2} \mathrm{ip} /$ (after vowel deletion) $\rightarrow / \mathrm{Pig}_{1,2}^{\mathrm{h}}{ }_{1, \mathrm{p}}$ /

\begin{tabular}{|c|c|c|c|c|}
\hline$/ \mathrm{Pih}_{1} \mathrm{~g}_{2} \mathrm{ip} /$ & MAX & DEP & *GlotTAL-Plosive & *COMPSEG \\
\hline a. $2 \mathrm{ih}_{1} \mathrm{~g}_{2} \mathrm{ip}$ & & & $* !$ & \\
\hline b. $\mathrm{Pig}_{1,2}^{\mathrm{h}}$ ip & & & & $*$ \\
\hline c. Pihip & $* !$ & & & \\
\hline d. Pihigip & & $* !$ & & \\
\hline
\end{tabular}

(20)

\begin{tabular}{|c|c|c|c|c|}
\hline$/ \mathrm{Prg}_{1,2}^{\mathrm{h}} \mathrm{ip} /$ & MAX & DEP & *GlotTAL-Plosive & *COMPSEG \\
\hline a. Pig $_{1,2}^{\text {h }}$ ip & & & & $* !$ \\
\hline b. $\operatorname{Pig}_{2} \mathrm{~h}_{1} \mathrm{ip}$ & & & & \\
\hline
\end{tabular}

How is the non-metathesis analysis in HS different from a P-OT analysis? Canfield (2015) provides a P-OT analysis of Balangao CC metathesis. She models the variable vowel deletion with a markedness constraint DELETEVOWELWHENAFFIXED (DVWA), and contextualizes LINEARITY constraints based on the observation that the metathesis of glottal + plosive segments occurs only when they originate in the same morpheme. Since the general LINEARITY constraint does not differentiate within-morpheme reordering from outsidemorpheme one, Canfield formulates separate morpheme-related LINEARITY constraints as in (21)

(21) Morpheme-related LINEARITY constraints (Canfield 2015: 88)

a. LINEARITY-OUTSIDE-MORPHEME:

Let $\mathrm{M}_{1}$ and $\mathrm{M}_{2}$ be morphemes. If $x \in \mathrm{M}_{1}$ and $y \in \mathrm{M}_{2}$, and $\mathrm{M}_{1}$ precedes $\mathrm{M}_{2}$ in a string $\mathrm{S}_{1}$, and $x$ immediately precedes $y$ in $\mathrm{S}_{1}$, then if $x \Re x^{\prime}$ and $y \mathfrak{R} y^{\prime}$ in $\mathrm{S}_{2}$, then $x^{\prime}$ immediately precedes $\mathrm{y}^{\prime}$ in $\mathrm{S}_{2}$.

b. LINEARITY-WITHIN-MORPHEME:

If $x y \in \mathrm{M}_{1}$, and $x \boldsymbol{R} x^{\prime}$ and $y \boldsymbol{R} y^{\prime}$, and $x$ immediately precedes $y$ in $\mathrm{S}_{1}$, then $x^{\prime}$ immediately precedes $y^{\prime}$ in $\mathrm{S}_{2}$.

Utilizing those two constraints, Canfield (2015) derives the correct outputs with and without metathesis.

\footnotetext{
3 Padgett (2005) considers that laryngeals do not violate * COMPSEG since they lack place of articulation features. I follow McCarthy (1989 cited in Fallon 1998) and assume that laryngeals have place specification as [pharyngeal]. Therefore, complex segments involving laryngeals violate *COMPSEG in the same way as do other types of complex segments.
} 
Balangao metathesis and non-metathesis case: (Adapted from Canfield 2015: 89)

a. /2i+higip/ $\rightarrow$ Pighip (metathesis applied)

\begin{tabular}{|c|c|c|c|c|c|c|}
\hline /Pì+higip/ & $\begin{array}{l}\text { LINEARITY- } \\
\text { OUTSIDE- } \\
\text { MORPHEME }\end{array}$ & DVWA & MAXC & DEP & $\begin{array}{l}\text { *GLOTTAL- } \\
\text { PLOSIVE }\end{array}$ & $\begin{array}{l}\text { LINEARITY- } \\
\text { WITHIN- } \\
\text { MORPHEME }\end{array}$ \\
\hline a. ?ighip & & & & & & * \\
\hline b. Pihgip & & & & & *! & \\
\hline c. Pigip & & & $* !$ & & & \\
\hline d. Pihip & & & $* !$ & & & \\
\hline e. ?ihigip & & *! & & & & \\
\hline
\end{tabular}

b. /Pumalihto/ $\rightarrow$ Pu.ma.lih.to (metathesis blocked)

\begin{tabular}{|c|c|c|c|c|c|c|}
\hline /Pumalih + to/ & $\begin{array}{l}\text { LINEARITY- } \\
\text { OUTSIDE- } \\
\text { MORPHEME }\end{array}$ & Dvwa & MAXC & DEP & $\begin{array}{l}\text { *GLOTTAL- } \\
\text { Plosive }\end{array}$ & $\begin{array}{l}\text { LINEARITY- } \\
\text { WITHIN- } \\
\text { MORPHEME }\end{array}$ \\
\hline a. Pu.ma.lit.ho & $* !$ & & & & & \\
\hline b. Pu.ma.lih.to & & & & & * & \\
\hline c. ?u.ma.li.to & & & $* !$ & & & \\
\hline d. ?u.ma.li.ho & & & $* !$ & & & \\
\hline e. Pu.ma.li.hi.to & & & & $* !$ & & \\
\hline
\end{tabular}

The analysis of Balangao proposed here which incorporates fusion + fission does not require a family of LINEARITY constraints. The blocking case of / ?umalih + to $/ \rightarrow$ ?u.ma.lih.to can be achieved simply by ranking CRispEdGe (Ito \& Mester 1994) above *GlotTAL-Plosive as shown in (23)

Blocking morpheme internal metathesis in Balangao with CrispEdge.

/Pumalih+to/ $\rightarrow\left[\right.$ Pumalih $\left._{1} \mathrm{t}_{2} \mathrm{O}\right]-$ fusion blocked at Step 1

Step 1: fusion / Pumalih $_{1}+\mathrm{t}_{2} \mathrm{O} / \rightarrow$ [?umalih $\left.\mathrm{t}_{2} \mathrm{O}\right]$

\begin{tabular}{|c|c|c|c|c|c|}
\hline / Pumalih $_{1}+\mathrm{t}_{2} \mathrm{O} /$ & MAX & DEP & CRISPEDGE & *GLOTTAL-PlOSIVE & *COMPSEG \\
\hline a. Pumalih ${ }_{1} \mathrm{t}_{2} \mathrm{O}$ & & & & * & \\
\hline b. Pumalit ${ }_{1,2}^{\mathrm{h}} \mathrm{O}$ & & & $* !$ & & $*$ \\
\hline c. . Pumalit ${ }_{2} \mathrm{O}$ & $*(!)$ & & & & \\
\hline d. Pumalih it $_{2} \mathrm{O}$ & & $*(!)$ & & & \\
\hline
\end{tabular}

One of the reasons why we might want to choose the fusion + fission analysis over other operations stems from an observation about the types of segments involved in CC metathesis. Hume (2002) cites Blevins and Garrett's (1998) observation that, "glottals, liquids and glides are commonly involved in metathesis" (Hume 2002: 19). Incorporating Blevins and Garrett's insight Hume speculates that those segments generally have acoustically longer cues, which can "extend over a domain which may encompass adjacent sounds," and can "result in the overlap of important phonetic cues potentially creating ambiguity concerning the onset and offset of the sounds involved." (p. 19). According to Hume's Ambiguity/Attestation model, these ambiguous cues are subject to re-interpretation and surface in the order which is more common in these languages. A fusion and fission analysis is in a sense a formalization of these insights.

Another important reason for preferring the fusion + fission analysis for $\mathrm{CC}$ metathesis is that there is a major distinction between $\mathrm{CV}$ and $\mathrm{CC}$ metathesis. Unlike $\mathrm{CV}$ metathesis in which any segments can undergo CV - VC alternation, as we observed in Rotuman or Kwara'ae, all of the attested CC metatheses pose restrictions on the types of segment involved. Only certain segments are involved in CC metathesis; a stop + a fricative, a glottal + a consonant, an obstruent + a liquid or a nasal, a consonant + a palatal, a velar stop + a labial stop, a velar stop + a coronal fricative. ${ }^{4}$ The constraint LINEARITY does not impose restrictions on which segments undergo metathesis. From the fusion + fission perspective, the restriction placed on segments in CC metathesis appears to be phonetically motivated and thus restricted to segments that are fuse-able.

\footnotetext{
4 The list was made based on Canfield (2016). There are a few cases not listed here that need further investigation in terms of segment types involved in apparent metathesis.
} 
Finally, another advantage of the fusion + fission analysis is that we see fusion and fission as independent operations. Fusion has been observed in languages such as Zoque $/ \mathrm{jt} / \rightarrow\left[\mathrm{t}^{\mathrm{j}}\right]$ (Sagey 1986 cited in Mielke and Hume 2001) and Korean $/ \mathrm{h}+\mathrm{k} / \rightarrow\left[\mathrm{k}^{\mathrm{h}}\right]$ (Kim 1977). Although rarer, fission cases have been reported as preaspiration, as in Icelandic /vak ${ }^{\mathrm{h}} \mathrm{na} / \rightarrow$ [vahkna] (Heimisdóttir 2014).

\section{Discussion and conclusion}

The analysis of metathesis in the OT framework has traditionally relied on the constraint LINEARITY, which has been argued to pose conceptual (Heinz 2005a) as well as empirical problems in deriving the correct surface patterns in Parallel-OT (e.g., Carpenter 2002, Heinz 2005a, Canfield 2015). Additionally, as I have shown, gradual GEN cannot always block undesirable patterns from surfacing in HS if we assume transposition to be an atomic operation. I have demonstrated, through analysis of synchronic CV metathesis in Rotuman, that under Harmonic Serialism we do not require transposition as a phonological operation in deriving the correct restrictive patterns. Assuming that metathesis is composed of sequences of primitive operations such as copy + deletion, HS offers a simpler analysis without resorting to a family of LINEARITY/CONTIGUITY/ADJACENCY constraints, which otherwise would be necessary in P-OT analyses. A non-metathesis analysis correctly blocks undesirable patterns that arise in a serial OT analysis. Removing metathesis from possible operations also has the advantage of keeping the inventory of operations in GEN simple which is in line with the view that GEN can only make minimal changes, such as feature deletion (McCarthy 2016).

An analysis of metathesis in HS without assuming a reordering operation has not been proposed in the literature to the best of my knowledge. However, the sequential copy-and-deletion view of metathesis is not new. Postal (1969) and Michelson (1988) both analyze the CV? sequence to be underlyingly C?V, and analyze the alternation as copy and deletion, called in Postal (1969) Vowel Twin and Twin Reduction. Many others have suggested that certain synchronic or diachronic metathesis cases are the result of copy + deletion (e.g., Blevins and Garrett 1998, 2004, Heinz 2005, also see Chandlee 2014 for a review of relevant literature).

Although I do not provide full analyses here, various combinations of operations seem to be viable as candidate for replacing metathesis. The copy + deletion analysis can be extended to Palestinian Arabic (OSU 2017), Leti (van Engelenhoven 1994 cited in Hume 1998), and Kwara'ae (Heinz 2004). Fur (Jakobi 1990) and Hixkaryana (OSU 2017) can be analyzed as the result of epenthesis + assimilation + deletion, while consonant copy + deletion can derive Saanich (Stonham 1994) and Clallam (Thompson \& Thompson 1969) patterns.

As I have shown in this paper, a fusion + fission analysis can remove metathesis operations entirely from GEN. However, such an analysis is not without problems. A major issue is the lack of evidence for an intermediate stage which exhibits fusion but not fission. For instance, if we had observed an optional output [?ig $\left.{ }_{1,2}^{\mathrm{h}} \mathrm{ip}\right]$ for $/ \mathrm{Pih}_{1} \mathrm{~g}_{2} \mathrm{ip} / \rightarrow\left[\mathrm{Pig}_{2} \mathrm{~h}_{1} \mathrm{ip}\right]$ mapping in Balangao, this would be strong evidence to support the fusion + fission approach. Another potential issue is the rarity of consonant fission observed across languages. However, Staroverov (2014) proposes that consonant epenthesis is in fact splitting, which in my view is analogous to the fission operation. If consonant epenthesis is also a case of fission, it promotes the status of fission, making it a more frequently observed one. Alternatively, the rarity of fission operations might be connected to the rarity of CC metathesis. The reason why CC metathesis is not as frequent as other operations such as deletion or epenthesis might be that it involves fission, which itself is infrequently observed. Nevertheless, both fusion and fission are observed as independent operations across languages. Fallon (1998) summarizes independent fusion and fission cases with ejectives as reported in the literature and suggests that both should be considered to be basic operations. The proposed fusion + fission analysis predicts that 'fuse-able' consonant pairs are more susceptible to apparent metathesis. Artificial language experiments could provide us with more support for the fusion + fission view. Comparing different types of CC sequences to examine which are easier to learn might help provide additional evidence (see Finley 2016 for syllable structure effects on metathesis learning).

I have shown that the metathesis operation is not needed in HS, and that apparent cases of synchronic metathesis may be derived through sequential applications of simpler operations. By removing the single metathesis operation, the constraint LINEARITY becomes irrelevant, making most of the problems with LINEARITY disappear. Instead, unattested cases such as those involving long-distance dependencies and VV metathesis are prohibited via gradualness of GEN and constraints active in the given language, thus furthering our understanding of GEN in HS. Appealing to sequential applications of primitive operations also makes it 
possible to incorporate the phonetically-motivated generalization that certain segments are more susceptible to metathesis.

\section{References}

Besnier, Niko (1987). An autosegmental approach to metathesis in Rotuman. Lingua 73. 201-223.

Blevins, Juliette (1994). The bimoraic foot in Rotuman Phonology and Morphology. Oceanic Linguistics 33:2. 491-516.

Blevins, Juliette \& Andrew Garrett (1998). The origins of consonant-vowel metathesis. $\operatorname{Lg} 74$. 508-556.

Blevins, Juliette \& Sheldon P. Harrison (1999). Trimoraic feet in Gilbertese. Oceanic Linguistics 28:2. 203-230.

Blevins, Juliette \& Andrew Garrett (2004). The evolution of metathesis. In Bruce Hayes, Robert Kirchner, \& Donca Steriade (eds.) Phonetically based phonology. Cambridge: Cambridge University Press. 117-156.

Buckley, Eugene (2011). Metathesis. In Marc van Oostendorp, Colin J. Ewen, \& Elizabeth V. Hume (eds.) The Blackwell Companion to Phonology 3. Massachusetts: Wiley-Blackwell. 1380-1470.

Canfield, Tracy A. (2015). Metathesis is real, and it is a regular relation. PhD dissertation, Georgetown University.

Carpenter, Angela (2002). Noncontiguous metathesis and adjacency. In Angela Carpenter, Andries Coetzee \& Paul de Lacy (eds.) Papers in Optimality Theory II. Amherst: GLSA. 1-26.

Chandlee, Jane (2014). Strictly local phonological processes. PhD dissertation, University of Delaware.

Churchward, C. Maxwell (1940). Rotuman Grammar and Dictionary. Sydney: Australasia Medical Publishing Co.

Eisner, Jason (1997). What Constraints Should OT Allow? Talk handout, Linguistic Society of America, Chicago. Available on the Rutgers Optimality Archive, ROA\#204-0797, http://roa.rutgers.edu/.

Elfner, Emily (2016). Stress-epenthesis interactions in Harmonic Serialism. In McCarthy, John J., \& Joe Pater (eds.), Harmonic grammar and harmonic serialism. United Kingdom: Equinox. 261-300.

Fallon, Paul D. (1998). The synchronic and diachronic phonology of ejectives. PhD dissertation, Columbus, Ohio: Ohio State University.

Finley, Sara Rose (2017). Learning metathesis: Evidence for syllable structure constraints. Journal of Memory and Language 92. 142-157.

Hale, Mark \& Madelyn Kissock (1998). The phonology-syntax interface in Rotuman. In Matthew Pearson (ed.), Recent Papers in Austronesian Linguistics: Proceedings of the $3^{\text {rd }} \& 4$ th Meetings of the Austronesian Formal Linguistics Society, UCLA Occasional Papers in Linguistics 21, Los Angeles: UCLA Department of Linguistics. 115-128.

Hale, Mark. \& Madelyn Kissock (2011). Is Harmonic Serialism Serial Enough? Paper presented at the 8th Old World Conference on Phonology, Marrakesh, Morocco, January, 16-22.

Hayes, Bruce (1995). Metrical Stress Theory: Principles and Case Studies. Chicago: The University of Chicago Press.

Heimisdóttir, Linda Ö. (2014). Phonological opacity and Icelandic preaspiration. Proceedings of the 37th Annual Penn Linguistics Conference. 141-149.

Heinz, Jeffrey (2004). CV Metathesis in Kwara'ae. MA thesis. University of California, Los Angeles. Available at http://www.linguistics.ucla.edu/people/grads/jheinz/.

Heinz, Jeffrey (2005a). Reconsidering linearity: Evidence from CV metathesis. WCCFL 24. 200-208.

Heinz, Jeffrey (2005b). Optional partial metathesis in Kwara'ae. UCLA Working Papers in Linguistics. 91-102.

Hume, Elizabeth V. (1998). Metathesis in phonological theory: The case of Leti. Lingua 104:3-4. 147-186.

Hume, Elizabeth V. (2001). Metathesis: formal and functional considerations. In Elizabeth V. Hume, Norval Smith \& Jeroen van de Weijer (eds.) Surface syllable structure and segment sequencing. Leiden: HIL. 1-25.

Hume, Elizabeth V. (2004). The indeterminacy/attestation model of metathesis. $\mathrm{Lg}$ 80. 203-237.

Inkelas, Sharon (1994). Exceptional stress-attracting suffixes in Turkish: Representations versus the grammar. Ms., University of California, Berkeley.

Ito, Junko., \& Amin Mester (1994). Reflections on CodaCond and Alignment. In Rachel Walker, Jaye Padgett \& Jason Merchant. (eds.) Phonology at Santa Cruz 3. Santa Cruz: Linguistics Research Center. 27-46.

Jakobi, Angelika (1990). A Fur grammar: Phonology, morphophonology and morphology. Hamburg: Buske Verlag.

Johnson, Douglas C. (1982). Vowel-consonant metathesis in a Palestinian dialect. Acta Linguistica Hafniensia 17:1. 6177.

Kim, Chin-Wu (1977). Rule ordering in Korean phonology. Korean Studies 1. 1-20. University of Hawaii Press.

McCarthy, John J. (1995). Faithfulness in prosodic morphology and phonology: Rotuman revisited. Ms, University of Massachusetts Amherst.

McCarthy, John J. (2000a). The prosody of phase in Rotuman. NLLT 18. 147-197.

McCarthy, John J. (2000b). Harmonic serialism and parallelism. In Masako Hirotani (ed.), NELS 30. Amherst: MA 
GLSA. 501-524.

McCarthy, John J. (2007a). Hidden Generalizations: Phonological Opacity in Optimality Theory. London: Equinox.

McCarthy, John J. (2007b). Restraint of analysis. In Sylvia Blaho, Patrik Bye, \& Martin Krämer (eds.), Studies in generative grammar: 95. Freedom of analysis. Berlin: Mouton de Gruyter. 203-231.

McCarthy, John J. (2010). An introduction to harmonic serialism. Language and Linguistics Compass. 4:10. 1001-1018.

McCarthy, John J (2016) The theory and practice of Harmonic Serialism. In John J. McCarthy \& Joe Pater (eds.), Harmonic Grammar and Harmonic Serialism. London: Equinox.

McCarthy, John. J. \& Alan S. Prince (1994). The emergence of the unmarked: Optimality in Prosodic Morphology. In Merce Gonzàlez (ed.), NELS 24. 333-379.

McCarthy, John J. \& Alan S. Prince. (1995). Faithfulness and reduplicative identity. In Jill N. Beckman, Laura Walsh Dickey, \& Suzanne Urbanczyk (eds.), Papers in Optimality Theory, University of Massachusetts Occasional Papers 18. Amherst: Graduate Linguistic Student Association, Dept. of Linguistics, South College, University of Massachusetts. 249-384.

McCarthy, John J. \& Joe Pater (eds.) (2016). Harmonic Grammar and Harmonic Serialism. London: Equinox.

Michelson, Karin (1988). A Comparative Study of Lake-Iroquoian Accent. Dordrecht: Kluwer Academic Publishers.

Mielke, Jeffrey \& Elizabeth Hume (2001). Consequences of word recognition for metathesis. In Elizabeth Hume, Norval Smith, \& Jeroen van de Weijer (eds.), Surface Syllable Structure and Segment Sequencing. Leiden: HIL. 135158.

Ohio State University (2011). Metathesis. Retrieved from http://www.ling.ohio-state.edu/ ehume/metathesis/.

Padgett, Jaye (1995). Feature classes. In Jill N. Beckman, Laura Walsh Dickey \& Suzanne Urbanczyk (eds.), Papers in Optimality Theory, University of Massachusetts Occasional Papers 18. Amherst: GLSA, 385-420.

Pater, Joe (2003). Balantak metathesis and theories of possible repair in Optimality Theory. Ms., Amherst: UMass.

Postal, Paul M. (1969). Mohawk vowel doubling. IJAL 35:4, 291-298.

Prince, Alan (1990). Quantitative consequences of rhythmic organization. In Deaton, Karen, Manuela Noske, \& Michael Ziolkowski (eds.) CLS 26-II. Chicago: Chicago Linguistics Society. 355-398.

Prince, Alan and Paul Smolensky (1993/2004). Optimality Theory: Constraint Interaction in Generative Grammar. Malden, MA: Blackwell.

Pruitt, Kathryn (2012). Stress in Harmonic Serialism. PhD dissertation, University of Massachusetts Amherst.

Shelter, Joanne (1976). Notes on Balangao grammar. Huntington Beach, Calif.: SIL Asian-Pacific Series.

Stanton, Juliet, \& Sam Zukoff (2015). Prosodic effects of segmental correspondence. In Proceedings of CLS 51, 501515 .

Staroverov, Petr (2014). Splitting theory and consonant epenthesis. PhD Dissertation, Rutgers University.

Stonham, John (1994). Combinatorial Morphology. Amsterdam: John Benjamins.

Thompson, Laurence C. \& M. Terry Thompson (1969). Metathesis as a grammatical device. IJAL 35:3, 213-219.

Torres-Tamarit, Francesc, Clàudia Pons-Moll, \& Maria Cabrera-Callís (2012). Rhotic metathesis in Algherese Catalan: a Harmonic Serialism account. In Kimberly Geeslin \& Manuel Díaz-Campos (eds.) Selected Proceedings of the 2010 Hispanic Linguistics Symposium, Somerville, MA: Cascadilla Proceedings Project, 354-364. 